\title{
Studies of the epidemiology of peptic ulcer in a rural community: prevalence and natural history of dyspepsia and peptic ulcer
}

\author{
R. DEANS WEIR AND E. MAURICE BACKETT \\ From the Department of Public Health and Social Medicine, University of Aberdeen
}

Underlying any description of the prevalence and natural history of peptic ulceration is the problem of definition. The classification of patients (and much of their treatment) will depend upon the severity and persistence of symmptoms, individual tolerance, the experience, work load and interests of the doctor, and the extent and availability of local facilities for diagnosis. These sources of variation could render studies of prevalence and natural history so inaccurate as to be hardly worth making. Yet without some understanding of how the peptic ulcer syndrome comes and goes in a total population, the study of its epidemiology is frustrated. The survey reported here attempted both an estimate of prevalence and to describe the natural history of the peptic ulcer syndrome over a three-year period in a semi-rural population of men.

\section{PURPOSE AND ORGANIZATION OF STUDIES}

The organization of the four related studies (of which the first is reported here) is summarized in the

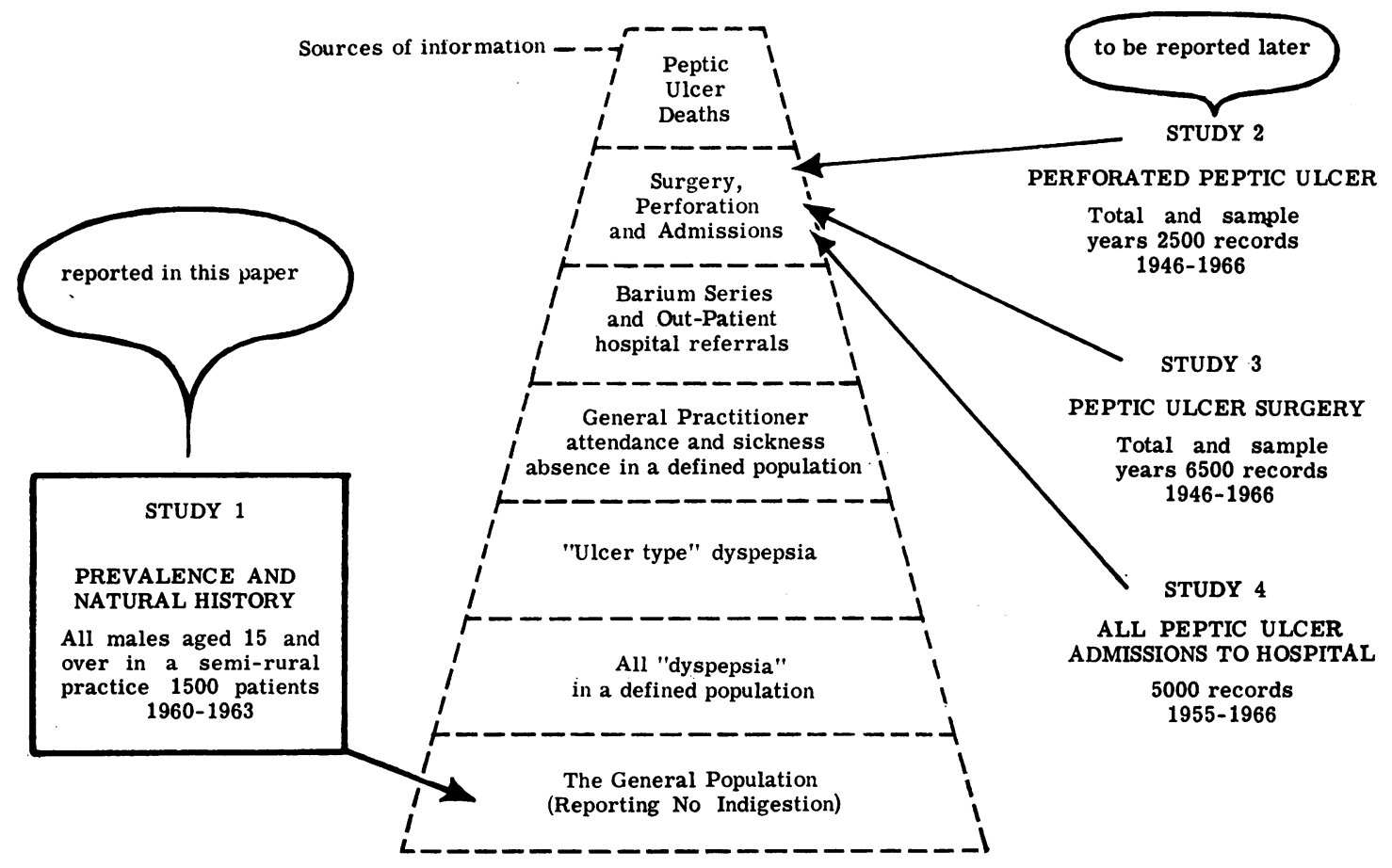

FIG. 1. Organization of four related studies. 
diagram (Fig. 1). In the figure the base of the pyramid represents the general population who have no stomach trouble or do not report it. Next, are those who complain of or admit to 'dyspepsia' or 'indigestion'. The third group suffer from typical ulcer-like dyspepsia. The fourth group have lost work or attended the doctor because of dyspepsia. Above these is a group who have had a barium meal or attended the out-patient department of a hospital because of dyspepsia. Next are the patients who have been admitted to hospital for investigation, for surgery, or because of a perforation or haematemesis. Finally, at the apex, are the few people who die as a result of a peptic ulcer.

The object of these studies was to show the relationship between dyspepsia and peptic ulceration, to estimate their prevalence and importance in a number of ways (mortality, work loss, attendance at the doctor, hospital referral, etc.), and to observe their associations with various ways of living. It was also hoped to add up-to-date Scottish material to the classic studies of Doll, Jones, and Buckatzsch (1951), Pulvertaft (1959), and others.

The present study is concerned with the ascertainment of the point and period prevalences, case inception, and natural history of dyspepsia and established peptic ulcer in males aged 15 and over in a semirural practice of some 1,500 male patients during the three-year period 1960-63 (initially by a postal enquiry and followed later by interview and both postal enquiry and interview repeated after an interval of three years and supplemented by medical records).

\section{METHOD}

In 1959 a small and nearly static population was defined in a semirural area of north-east Scotland. In it all aspects of the medical care of dyspepsia could be monitored for a period of at least three years. To this picture of medical care would be added information from repeated standard questionnaires supplemented by interviews with a stratified random sample of the whole population. The area chosen ${ }^{1}$ for the survey had other advantages: there is no choice of hospital for treatment (all services being centred upon the Aberdeen hospitals) and there is little movement of population in the area or between general practitioners. The cooperation of this population with medical surveys was well known, though the high figures actually achieved-over $99 \%$ for the first questionnaire-were not expected.

SOURCES OF INFORMATION Information about the population was obtained during three years from five linked sources: $(a)$ replies received from postal questionnaires; (b) records of medical interviews conducted during

${ }^{1}$ This was not a representative sample but a total population registered with three general practitioners. home visits; (c) general practice records; $(d)$ hospital outpatient records; and $(e)$ hospital inpatient records.

Evidence from repeated double checks suggests that losses of records of attendance, etc., from each source were negligible-perhaps of the order of 2 to $3 \%$ over the three-year period.

The postal enquiries All males over the age of 15 years registered with three practitioners were approached through a postal enquiry signed by their family doctor. Such an approach achieved rapid identification of the majority of patients, permitted the practice records to be brought up to date regarding marital state and occupation etc., and allowed a screening procedure, on the basis of answers about dyspepsia ${ }^{2}$, to provide groups suitable for sampling and subsequent interview.

CATEGORIES OF DYSPEPSIA Replies were divided into three main categories of apparent severity ('major dyspepsia', 'minor dyspepsia', and 'no dyspepsia').

Major was deemed to consist of (1) diagnosed peptic ulcer i.e., patients in whom a lesion had been demonstrated surgically or radiologically; (2) 'likely' peptic ulcer i.e., patients with similar symptoms to those with diagnosed ulcer but in whom, despite investigation, it was not possible to demonstrate an ulcer.

Minor was deemed to consist of (1) 'ulcer-like' dyspepsia patients reporting dyspepsia who had been attending the doctor because of their symptoms, but who had not been further investigated. (2) 'Other' dyspepsia, patients reporting dyspepsia but who had not consulted the doctor concerning their symptoms. (3) 'No dyspepsia, was deemed to consist of (1) 'doubtful' dyspepsia, patients apparently failing to understand the form, entering an unrelated operation or condition (e.g. appendicectomy, or hernia) or who were subsequently diagnosed as suffering from some other condition (e.g. diverticulitis), and (2) 'negative' responders, patients with no present or recollected dyspepsia in the previous five years.

PERIODS OF DYSPEPSIA The three periods when dyspepsia symptoms were experienced ('current dyspepsia', 'recent dyspepsia', and 'past dyspepsia') made another category.

'Current' Patients who said they had experienced symptoms of dyspepsia within three months of the enquiry.

'Recent' Patients who said they had experienced dyspepsia during the preceding five years (but were free of symptoms for more than three months at the time of the enquiry).

'Past' Patients who had complained of dyspepsia but had experienced no symptoms in the five years preceding the enquiry.

Because it is impossible to verify statements about past dyspepsia the category is not used in any of the tabulations. Men with a 'past demonstrable ulcer' when included in 'major' dyspepsia are stated as such; men with 'past ulcer-like dyspepsia' are referred to in the discussion.

'The questions concerning dyspepsia (Appendix A) were very similar to those used by Doll, Jones, and Buckatzsch (Doll et al., 1951), but included questions about barium-meal examinations and the medical actions taken as a result of dyspepsia. 
Using this classification, the following dyspepsia categories are possible:

\begin{tabular}{lll} 
Period & \multicolumn{1}{l}{ Severity } \\
\hline $\begin{array}{l}\text { Current } \\
\text { Recent } \\
\text { Past }\end{array}$ & Major Groups & Sub Categories \\
\cline { 2 - 3 } $\begin{array}{l}\text { Current } \\
\begin{array}{l}\text { Recent } \\
\text { Past }\end{array}\end{array}$ & (2) Major dyspepsia & $\begin{array}{l}\text { Diagnosed peptic ulcer } \\
\text { 'Likely' peptic ulcer }\end{array}$ \\
- & & 'Ulcer-like' dyspepsia \\
- & (3) No dyspepsia & 'Other' dyspepsia \\
& & 'Doubtful' dyspepsia \\
& & 'Negative' responders
\end{tabular}

As each item of information about individuals in the study became available it was possible to classify them with more assurance and to distinguish errors of reporting from true changes in the natural history of the condition.

THE STANDARD MEDICAL INTERVIEWS The responses to each postal enquiry were checked against a standardized medical interview of a random sample of men from both the 'positive' and 'negative' groups, i.e. from those denying and reporting dyspepsia symptoms. There were 140 men in the 'positive' group and 144 men in the 'negative' group at the beginning of the study. These were interviewed and all cooperated fully. After the second postal enquiry the same random sample of positive and negative groups was again interviewed. At interview the men were asked the same five standard questions about dyspepsia, haematemesis, gastric surgery, barium-meal examinations, and diagnosed peptic ulceration which had featured in the postal survey (Appendix A). Where relevant, further details about dyspepsia were requested and finally, additional standard questions were asked of some patients when the responses indicated a change from their original replies. Almost all of the patients originally interviewed (i.e. all those who had not moved out of the area or died) were revisited after the second postal enquiry. This procedure allowed some measure of the observer error involved in the first interview study, as well as a check upon replies to the postal enquiry. The interviewing doctor knew only whether the patient acknowledged or denied dyspepsia and during the interviews (which took place in the patients' own homes) no mention was made of the postal questions relating to dyspepsia. After the completion of a standard questionnaire by the doctor at interview, the patient was classified according to his complaint, that is, he was placed in one of the dyspepsia groups (above).

GENERAL PRACTITIONER AND HOSPITAL RECORDS After the second postal enquiries and interviews had been completed, the replies from both sources were checked against the records of the general practitioners and records of surgery attendances, all hospital contacts, and radiographs. As part of a continuing study a record of all peptic ulcer admissions to hospitals in the region since 1946 has been maintained and all reports within this index relating to individuals in the study were identified and then linked with the general practice records of the same individual.
The same sequence was followed for out-patient attendances and radiographs. ${ }^{1}$

\section{RESULTS}

1 THE INITIAL SURVEY OF DYSPEPSIA The records of a total population of 1,703 men allegedly aged 15 years and over were available at the beginning of the survey. This number dropped to 1,494 when all those under age 15 , dead, or having left the area, were eliminated. Of these 1,494 , over 1,300 responded at once to the postal questionnaire and after a reminder only 92 people had to be visited to obtain their cooperation. Ultimately, 1,487 men over age 15 were included in the survey. The response to the postal questionnaire is given in Table $\mathbf{I}$.

\section{TABLE I}

\section{RESPONSE TO THE POSTAL ENQUIRIES}

\begin{tabular}{|c|c|c|c|}
\hline First Enquiry 1960 & & Second Enquiry 1963 & \\
\hline $\begin{array}{l}\text { Initial register compiled } \\
\text { from Executive Council }\end{array}$ & & $\begin{array}{l}\text { Number actually replying } \\
\text { to the first postal enquiry }\end{array}$ & 1,487 \\
\hline $\begin{array}{l}\text { Lists and general practice } \\
\text { wallets }\end{array}$ & 1,703 & & \\
\hline $\begin{array}{l}\text { Found to have died, left } \\
\text { the area and under age } 15\end{array}$ & 209 & $\begin{array}{l}\text { Known to have left area } \\
\text { Known to have died }\end{array}$ & $\begin{array}{l}48 \\
46\end{array}$ \\
\hline Total & 1,494 & Total & 1,393 \\
\hline Replies to first letter & 1,052 & Replies to first letter & 702 \\
\hline Replies t & 269 & Replies to second letter & 364 \\
\hline Replies to third letter & 81 & Replies to third letter & 149 \\
\hline & & Replies to fourth letter & \\
\hline $\begin{array}{l}\text { Replies following a home } \\
\text { visit }\end{array}$ & 85 & $\begin{array}{l}\text { Replies following a home } \\
\text { visit }\end{array}$ & 56 \\
\hline & & $\begin{array}{l}\text { Additional persons: } \\
\text { Found to have died }\end{array}$ & \\
\hline & & Found to have left area & 62 \\
\hline Total replies & 1,487 & Total replies & 1,392 \\
\hline Patients not cooperating & 7 & Patients not cooperating & 1 \\
\hline Total & 1,494 & Total & 1,393 \\
\hline
\end{tabular}

First medical interview Although 284 men were included in the sample to be interviewed (140 'positives' and 144 'negatives'), 11 had either left the area or died before all the interviews were carried out. The results of the interviews and comparison with the original postal responses are shown in Table II. From this Table it will be seen that the postal questionnaire leads to some understatement of the extent of dyspepsia measured at interview.

2 THE SECOND SURVEY OF DYSPEPSIA The second postal survey after three years produced responses from all but 79 men out of the 1,487 who had been surveyed three years before. Eventually, a further 59 replies were received. Of the remaining 20 men, 19 were found to have left the area and one man, although still living in the district, could not be contacted. This survey provided 1,328 completed records. One hundred and fifty-nine more were

'There is a 'direct access' scheme operating in the area which enables general practitioners to order their own barium series. 
TABLE II

COMPARISON OF TWO METHODS OF MEASURING THE PREVALENCE OF DYSPEPSIA IN THE SAME POPULATION ${ }^{1}$

Dyspepsia Classification

\begin{tabular}{lllll} 
Negative & Sample & & \multicolumn{2}{l}{ Positive Sample } \\
\cline { 1 - 1 } $\begin{array}{l}\text { Postal } \\
\text { Enquiry }\end{array}$ & $\begin{array}{l}\text { Medical } \\
\text { Interview }\end{array}$ & $\begin{array}{l}\text { Postal } \\
\text { Enquiry }\end{array}$ & $\begin{array}{l}\text { Medical } \\
\text { Interview }\end{array}$ \\
\hline 137 & 112 & Nil & 1
\end{tabular}

Negative responses

137

112

Doubtful responses

Haematemesis, operation,

and/or barium meal but

no diagnosis Nil

Other doubtful replies Nil

Current and recent minor dyspepsia

Dyspepsia associated

with food, no contact

with doctor

Dyspepsia and taking

antacids only

Nil

Nil

7

20

18

Having seen doctor in

last five years because of

dyspepsia but no

diagnosis

Nil

24

28

Current and recent major dyspepsia

Having seen doctor in

last five years plus a

barium meal or out-

patient attendance

because of dyspepsia but

no diagnosis

indigestion in last five

years

Nil

Nil

12

20

Past major dyspepsia

Total

Nil
Nil
137

Nil

29

26

Nil

137

10

136

12

12
136

${ }^{1}$ Differences recorded from postal questionnaire by subsequent standard medical interview in two random samples of respondents: 137 reporting no dyspepsia (the negative sample) in the last five years and 136 reporting dyspepsia (the positive sample) at the postal enquiry (males in north-east Scotland, 1961)
TABLE III

THE RESPONSE TO THE SECOND POSTAL ENQUIRY (AFTER A THREE-YEAR INTERVAL) ${ }^{1}$

Complete records obtained

Deaths (since first survey) ${ }^{2}$

Known to have left area

Untraced

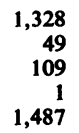

(89.4\%)

$(3 \cdot 2 \%)$

$(7 \cdot 3 \%)$

$\left(-\frac{1}{2} \%\right)$

${ }^{1}$ The questionnaire is detailed in Appendix A

${ }^{2}$ None was from peptic ulcer or its complications

incomplete because the patients had either died (49) or left the area between the two enquiries (109) (Table III).

The survivors of the random sample of 140 'positive' responders and the survivors of the 144 'negative' responders defined at the first enquiry were again interviewed. The results of these interviews were again used as a check upon the validity of the postal replies. However, it is only by scrutiny of the individual experience of each man during the three years that the natural history of the condition emerges. This can be inferred from a comparison of the two postal surveys (Table IV).

CHANGES OBSERVED BETWEEN THE FIRST AND SECOND SURVEY Certain changes were observed in the patterns of reported dyspepsia between the first and second surveys, and these have been broken down as follows:

295 men with 'current ulcer-like dyspepsia' at first enquiry Of the men experiencing dyspepsia symptoms at the time of the first enquiry, $65 \%$ still reported current symptoms at the second enquiry and

\section{TA BLE IV}

CHANGES IN THE PATTERNS OF DYSPEPSIA IN THE SAME POPULATION ${ }^{1}$

Ulcer-like Dyspepsia

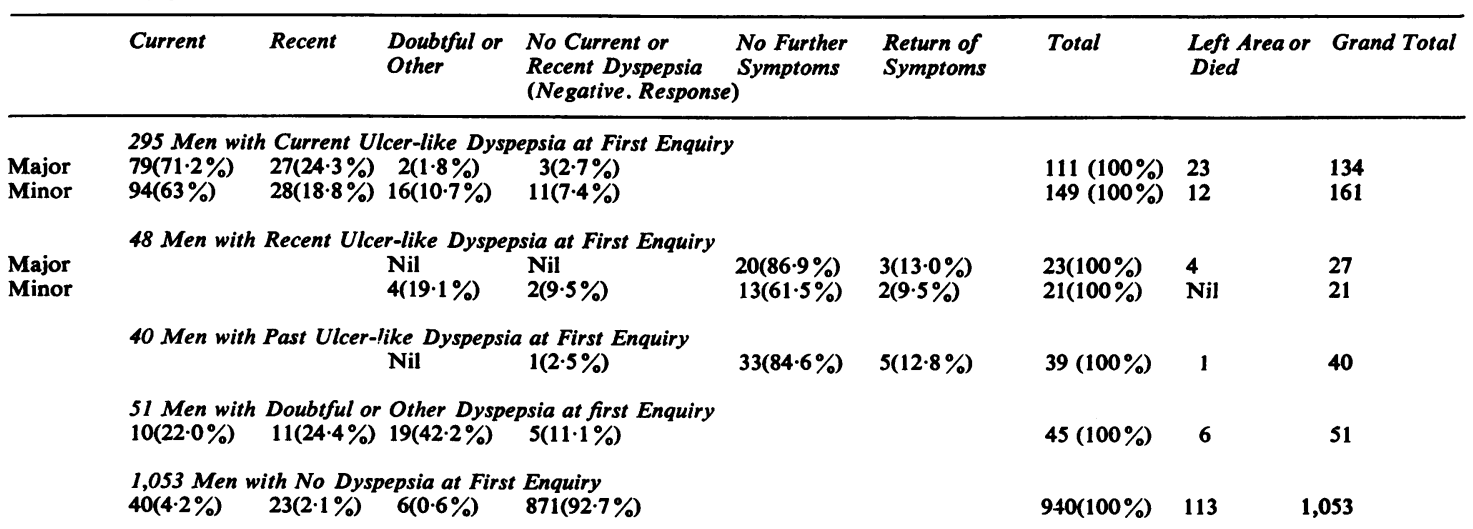

'Differences recorded by identical postal questionnaires for 1,053 respondents reporting no dyspepsia (the negative responders) and 434 reporting dyspepsia (the positive responders) at the time of the first enquiry when requestioned three years later. 
$21 \%$ reported that they had experienced no further symptoms during the three years. Of the remaining men, $7 \%$ although mentioning dyspepsia, gave an unconvincing and, therefore, doubtful response, and $5 \%$ denied ever having dyspepsia at any time: these men represent the small but inevitable number of contradictory replies associated with unverified postal responses.

48 men with 'recent ulcer-like dyspepsia' at first enquiry Most of the men who, although not experiencing symptoms at the time of the first enquiry, acknowledged that they had suffered symptoms in the previous five years, did so again on the second occasion; $10 \%$ of these men had experienced a return of symptoms during the three-year interval and another $10 \%$ gave, on the second occasion, a doubtful and therefore inconsistent response.

40 men with 'past ulcer-like dyspepsia' at the first enquiry Most of these men again indicated that although they had once been diagnosed as suffering from peptic ulcer they were not experiencing any symptoms; $12 \%$, however, had experienced a return of symptoms during the three years and acknowledged 'current dyspepsia' at the second enquiry.

51 men with 'doubtful (or otherwise diagnosed) dyspepsia' at first enquiry This group presented the greatest apparent inconsistency at the second enquiry. Only $19(40 \%)$ of these men gave a similar response, again indicating doubtful or other dyspepsia and five $(11 \%)$ denied any earlier complaint of dyspepsia. One fifth (22\%) acknowledged symptoms suggestive of current ulcer-like dyspepsia and one quarter $(24 \%)$ gave replies differing from their initial response by suggesting that they had experienced recent ulcerlike dyspepsia.

1,053 men with no dyspepsia at first enquiry The majority of the men replying to the second enquiry again denied dyspepsia and were classed as negative responders. However, during the three years, 69 men previously free from symptoms either developed (or acknowledged) dyspepsia. Forty $(4 \cdot 2 \%)$ of these men were experiencing symptoms of current ulcerlike dyspepsia, $23(2 \cdot 1 \%)$ symptoms of recent ulcerlike dyspepsia, and six symptoms of doubtful dyspepsia. This gives a potential ${ }^{1}$ case inception rate of 69 in 1,053 men, or 22 per 1,000 per annum for 'all dyspepsia' and 12 per 1,000 per annum for 'ulcer-like dyspepsia'.

3 SUPPORTING EVIDENCE COLLECTED AFTER THE SECOND ENQUIRY: HOSPITAL AND PRACTICE RECORDS Following the second survey an examination of hospital and general practitioner records, of the kind now possible in the north-east of Scotland (Weir, 1960), was made to verify and to expand responses that had been given. This made a final classification possible and more accurate period prevalence rates were computed (Table V). For the main changes in pattern, however, it is necessary to use the less accurate material from the postal and interview surveys.

The prevalence of dyspepsia is greatest from age 25 to 44 years while demonstrable peptic ulceration is more common after 45 years of age. On the other hand, the incidence of dyspepsia (in this case measured over three years) is more common in men under age 35 and over age 65 . As might be expected, the incidence of demonstrable ulcers is more evenly spread throughout all the age groups. Duodenal ulcers constitute the majority of demonstrable lesions ascertained during the survey and of the total 143 diagnosed ulcers only seven had been classified as gastric.

${ }^{1}$ Based on the unverified postal responses.

TABLE V

PREVALENCE AND INCIDENCE OF DYSPEPSIA AND PEPTIC ULCERATION IN 1,328 SURVIVORS FOLLOWING THE EXAMINATION OF HOSPITAL AND PRACTITIONER RECORDS

\begin{tabular}{|c|c|c|c|c|c|c|c|c|c|c|c|c|c|c|}
\hline \multirow[t]{3}{*}{ Dyspepsia Group } & \multicolumn{12}{|c|}{ Age Group (yr) } & \multicolumn{2}{|c|}{ Total } \\
\hline & \multicolumn{2}{|c|}{$15-24$} & \multicolumn{2}{|c|}{$25-34$} & \multicolumn{2}{|c|}{$35-44$} & \multicolumn{2}{|c|}{$45-54$} & \multicolumn{2}{|c|}{$55-64$} & \multicolumn{2}{|c|}{64 and Over } & \multirow[t]{2}{*}{ No. } & \multirow{2}{*}{$\begin{array}{l}\text { Ratel } \\
1,000\end{array}$} \\
\hline & No. & $\begin{array}{l}\text { Ratel } \\
1,000\end{array}$ & No. & $\begin{array}{l}\text { Ratel } \\
1,000\end{array}$ & No. & $\begin{array}{l}\text { Ratel } \\
1,000\end{array}$ & No. & $\begin{array}{l}\text { Rate/ } \\
1,000\end{array}$ & No. & $\begin{array}{l}\text { Ratel } \\
\text { 1,000 }\end{array}$ & No. & $\begin{array}{l}\text { Ratel } \\
1,000\end{array}$ & & \\
\hline $\begin{array}{l}\text { Vague dyspepsia } \\
\text { (a) Period prevalence } \\
\text { (b) Three-year incidence }\end{array}$ & $\begin{array}{r}16 \\
8\end{array}$ & $\begin{array}{l}64 \\
32\end{array}$ & $\begin{array}{r}17 \\
6\end{array}$ & $\begin{array}{l}76 \\
27\end{array}$ & $\begin{array}{r}22 \\
3\end{array}$ & $\begin{array}{l}87 \\
12\end{array}$ & $\begin{array}{r}13 \\
1\end{array}$ & $\begin{array}{r}53 \\
4\end{array}$ & $\begin{array}{r}10 \\
1\end{array}$ & $\begin{array}{r}50 \\
5\end{array}$ & $\begin{array}{l}9 \\
3\end{array}$ & $\begin{array}{l}57 \\
19\end{array}$ & $\begin{array}{l}87 \\
22\end{array}$ & $\begin{array}{l}65 \\
16\end{array}$ \\
\hline $\begin{array}{l}\text { Presumptive and strongly } \\
\text { presumptive ulcer } \\
\text { (a) Period prevalence } \\
\text { (b) Three-year incidence }\end{array}$ & $\begin{array}{l}24 \\
10\end{array}$ & $\begin{array}{r}100 \\
40\end{array}$ & $\begin{array}{r}43 \\
7\end{array}$ & $\begin{array}{r}196 \\
31\end{array}$ & $\begin{array}{r}47 \\
4\end{array}$ & $\begin{array}{r}190 \\
16\end{array}$ & $\begin{array}{r}42 \\
4\end{array}$ & $\begin{array}{r}174 \\
16\end{array}$ & $\begin{array}{r}30 \\
5\end{array}$ & $\begin{array}{r}156 \\
25\end{array}$ & $\begin{array}{r}19 \\
4\end{array}$ & $\begin{array}{r}120 \\
25\end{array}$ & $\begin{array}{r}205 \\
34\end{array}$ & $\begin{array}{r}154 \\
26\end{array}$ \\
\hline $\begin{array}{l}\text { Diagnosed peptic ulcer } \\
\text { (a) Period prevalence } \\
\text { (b) Three-year incidence }\end{array}$ & $\begin{array}{l}5 \\
1\end{array}$ & $\begin{array}{r}20 \\
4\end{array}$ & 15 & $\begin{array}{l}67 \\
-\end{array}$ & $\begin{array}{r}28 \\
1\end{array}$ & $\begin{array}{r}110 \\
4\end{array}$ & $\begin{array}{r}42 \\
2\end{array}$ & $\begin{array}{r}170 \\
8\end{array}$ & 26 & $\frac{131}{-}$ & $\begin{array}{r}20 \\
1\end{array}$ & $\begin{array}{r}127 \\
6\end{array}$ & $\begin{array}{r}136 \\
5\end{array}$ & $\begin{array}{r}102 \\
4\end{array}$ \\
\hline
\end{tabular}




\section{DISCUSSION}

Peptic ulcer is of great importance as a cause of morbidity. Probably some five million working days are lost annually to this cause (Ministry of Pensions and National Insurance, 1958-61; Jones, 1959; Office of Health Economics, 1965). Reflecting this loss in production there is a loss in income of some $£ 12$ million and payments of sickness benefit of between $£ 4$ and $£ 5$ million. Medical care costs could hardly be less than $£ 7-£ 8$ million (Office of Health Economics, 1964). To this $£ 25$ million odd must be added a small premature mortality and an unknown cost to the community of the pain and domestic disturbance caused by the condition. Little is known of the aetiology of peptic ulcer and studies of its epidemiology may contribute in two ways. First, the temporal (including cohort), geographic, and social patterns made by peptic ulcer may contribute to our knowledge of its causes, and second, an understanding of the natural history of dyspepsia and peptic ulcer may be of value in treatment. After a long and important increase in incidence (Backett, 1960) there is at last some recession of the peptic ulcer syndrome taking place in Britain. Three features of its recent epidemiology support this trend. Mortality is falling (Registrar General, 1945-64), perforations are declining (Illingworth, Scott, and Jamieson, 1944; Weir, 1960; Mackay, 1966), and other traditional measures of morbidity (sickness absence, hospital admissions) also support this notion. However, proof of the extent of secular change depends upon the measures used, and these are usually poor indicators of the disease. The limitations imposed by the use of perforations of peptic ulcers as a measure of morbidity have already been demonstrated (Weir, 1960). The use of mortalty as a measure of prevalence is even less accurate and the conflicting interpretations which follow the use of these data have been widely discussed (e.g. Doll, 1952). Morbidity determined from sickness absence rates and hospital admissions is also suspect because the denominators are ill defined.

Although attractive, it is not feasible even to accept the number of hospital diagnosed ulcers as a true measure of community prevalence. Because the diagnosis depends upon the significance which the patient attaches to his symptoms as well as the credence his doctors give to them some ulcers will be missed. A study of all peptic ulcers in a community must therefore start from the extent of dyspeptic symptoms and be followed by long-term observation of sickness absence, hospital admission, perforation, etc., in relation to them. Symptoms as vague and transient as 'dyspepsia' are, of course, notoriously difficult to describe, but because it is of dyspepsia which most patients complain and since relatively few peptic ulcers are not associated with this symptom, it is the logical starting point of study.

The estimation of point prevalence of dyspepsia leaves unsolved the problem set by the characteristic remission and exacerbation of symptoms and may include irrelevant dyspepsia. A balance is necessary between the danger of including the symptoms of, for example diverticulitis, appendicitis, and other disorders in the category of 'minor dyspepsia', and the exclusion of ulcer patients whose symptoms fall below a similar threshold of complaint. Our approach is to allow the passage of time - and the establishment of period prevalence-to simplify an otherwise complicated pattern.

LIMITATIONS OF THE POSTAL SURVEY When the dyspepsia classifications following postal enquiry and interview are compared it appears that 25 people $(18 \%)$ reporting no symptoms by questionnaire had in fact suffered dyspepsia. This direction of change was expected because at the interview the men were carefully questioned and, therefore, acknowledged symptoms they had until then considered 'normal' or not of sufficient importance to mention. Four of these men undoubtedly had tried to hide the fact that they had severe indigestion (two had, in fact, attended their doctor years before with this complaint) and five more had symptoms either of marked severity or for a number of years. The other 16 suffered symptoms of only short duration or which caused only slight inconvenience.

These findings suggest that in the whole population under review some 50 men $(3.3 \%)$ with dyspepsia may have been missed by the postal questionnaire and about half of these preferred not to admit to their symptoms; in addition, it is likely that another 50 men, on close questioning, would also admit to 'some indigestion' which they themselves had considered relatively unimportant.

The comparison between the postal questionnaire and interview for the positive sample showed a reasonable agreement, although, as might be expected, the number of persons allocated to the doubtful groups was smaller following medical interview.

It did not appear that the postal method of enquiry inflated the general level or any particular category of dyspepsia and may, in fact, have failed to reveal about $5 \%$ of the men with this symptom. To this extent it may be considered a blunt instrument for ascertaining prevalence.

IMPLICATIONS Three features of the dyspepsiapeptic ulcer syndrome emerge from this survey. They are: $(a)$ the magnitude of the morbidity; $(b)$ the relationship between symptoms and demonstrable 
ulcers; $(c)$ the natural history of the disease in the three-year period.

(a) The magnitude of the morbidity If current and recent dyspepsia (both major and minor) are taken together, nearly one man in every four suffered from this syndrome. A diagnosis of peptic ulcer had been made at some time for one man in every eight. These north-east of Scotland prevalence rates are higher than those reported from elsewhere in Britain.

The social and economic consequences of these high rates will be discussed elsewhere. The extent of reported dyspepsia (even if the most conservative estimates only are taken) suggests that there is a great deal of illness (some of it untreated) in this population. But most dyspepsia is mild and at some time almost universal. Therefore, it is the size of the group seeking treatment that is important. That $50 \%$ of the severely dyspeptic men (and nearly one in three of all dyspepiics) should have a demonstrable peptic ulcer confirms the seriousness of their illnesses, while the fact that probably one in 10 of these dyspeptics loses his stomach or has some other major operation for his ulcer, further underlines the importance of the syndrome.

Some, at least, of the excess dyspepsia in this population is related to the exceptionally good relationship between doctors and patients in the area and the relatively small number of patients per doctor. This small list size (among other aspects of local general practice) ensures a high quality service in which all complaints of dyspepsia are likely-sooner or later-to be investigated. Since the prevalence of peptic ulcer must depend, to some extent, upon how diligent is the search for it, high quality care may well be a factor.

There remains that part of the excess which cannot be explained in these ways and which represents an actual regional excess of the syndrome in the area studied. This excess calls for further and more detailed study.

Comparison with other studies of prevalence Various surveys of dyspepsia have provided measures of 'point' prevalence or of 'have or have had' prevalence (Doll et al., 1951; Pulvertaft, 1959; United States National Health Survey, 1960; Dunn and Cobb, 1962), and some have surveyed a total population (e.g. Doll, Jones, and Buckatzsch in 'Occupational factors in the aetiology of gastric and duodenal ulcers', 1951). Although similar, the two studies are not strictly comparable and the work in London was carried out 15 years before the Aberdeen enquiry. However, the Aberdeen material has been recalculated so that comparison is possible (Table VI).

There appears to be some difference in the prevalence of dyspepsia and peptic ulcer between the
TABLE VI

PREVALENCE OF DYSPEPSIA AND LIKELY PEPTIC ULCERATION $^{1}$

\begin{tabular}{|c|c|c|}
\hline \multirow[t]{2}{*}{ Dyspepsia Category } & \multicolumn{2}{|c|}{$\begin{array}{l}\text { Prevalence of Dyspepsia and } \\
\text { Likely Peptic Ulceration }(\%)\end{array}$} \\
\hline & Aberdeen 1961 & London 1946 \\
\hline $\begin{array}{l}\text { Diagnosed peptic ulcer } \\
\text { Asymptomatic past diagnosed } \\
\text { peptic ulcer } \\
\text { Likely peptic ulcer }\end{array}$ & $\begin{array}{l}8 \cdot 0 \\
1 \cdot 9 \\
5 \cdot 2\end{array}$ & $\overline{1 \cdot 3}$ \\
\hline $\begin{array}{l}\text { All peptic ulcer } \\
\text { Ulcer-like dyspepsia } \\
\text { Other dyspepsia } \\
\text { Doubtful responses }\end{array}$ & $\left.\begin{array}{r}15 \cdot 1 \\
8 \cdot 1 \\
5 \cdot 6 \\
6 \cdot 4\end{array}\right\} 35 \cdot 2$ & $\left.\begin{array}{c}6 \cdot 5 \\
24 \cdot 9\end{array}\right\} 31$ \\
\hline
\end{tabular}

${ }^{1}$ Estimated at enquiries relating to the previous five years in males aged 15-64 years of age in north-east Scotland in 1961 and in London in 1946 (Doll et al., 1951)

The above figures refer to Aberdeen population age 15-64 years and not 15 years and over as in previous tables.

north and south of the country at the two periods. Four possibilities are suggested. Either (1) the disease is more common and serious in the north-east of Scotland; (2) the causes of the apparent decline in peptic ulceration have not reached the north of Scotland; (3) at one time a far greater number of men in this area must have suffered from dyspepsia and peptic ulcer (which is not really tenable); or (4) the differences shown are attributable to differences in survey techniques.

We are inclined to the conclusion that the dyspepsias were only slightly more common in the Aberdeen area in the early 1960s than they were in London fifteen years before, that peptic ulceration is quite a lot more common than it was in London (Table VI), and that not all of this difference is due to differing survey techniques.

(b) The relationship between symptoms and demonstrable ulcers The extent to which dyspepsia of various kinds may be used as an indicator of peptic ulceration is not clearly understood. Obviously an association exists, but it is not clear whether this remains constant or fluctuates, or indeed whether there is much to be gained from further study of it. Diagnosed peptic ulcers (if they are not seen through the gastroscope) must be large enough to be visible radiographically or bleed or perforate; inevitably, therefore, there are many ulcers which exist but are not discovered and the value of the diagnosis is thus in doubt. One measure which may be of comparative use is the proportion of established ulcers per thousand cases of dyspepsia of various kinds. In this study the final classification showed that 136 of the men had a diagnosed peptic ulcer (Table V). These men with an established ulcer represented the tip of the iceberg, the rest of which was made up of dyspepsia of varying severity. Next to the diagnosed 
ulcer patients were the 75 men whose symptoms suggested to their doctors that they undoubtedly had a peptic ulcer, and next to them were 149 men whose dyspepsia was of the ulcer type. Finally, there were 101 men with vague dyspepsia. Patients with established ulcers expressed as a rate of all dyspeptics ascertained in the survey (the most rigorous criterion), is therefore 305 per 1,$000 ; 43$ of the survey men who had had a gastrectomy for peptic ulcer in the past have been included in this rate as it is a fair (but not sure) assumption that had they not had this operation they would still have their ulcers. By including among the demonstrable ulcer group patients with strongly presumptive ulcers, the rate rises to 466 ulcers per 1,000 dyspeptics. Therefore, among those men with severe dyspepsia (i.e. both demonstrable and strongly presumptive ulcers and including the gastrectomized men, a total of 218 patients) the ulcer rate was nearly $50 \%$.

(c) The natural history of the disease in the threeyear period One thousand one hundred and thirtyseven men gave a consistent reply at the beginning and the end of the three-year period; 22 changed from 'ulcer-like dyspepsia' to 'doubtful' and 21 from 'doubtful' to 'ulcer-like'; 69 men recorded a remission of their symptoms and 60 men acknowledged the start or return of symptoms (Table IV). If such a trend were to continue then dyspepsia in the population would gradually decline. Nevertheless, 'recent dyspepsia' was more commonly recorded on the second occasion and the full significance of this finding would require a further examination of the same population in another five to eight years. Four per cent of men originally reporting 'current ulcer-like dyspepsia' failed to confirm, on the second occasion, their initial response but otherwise the majority of replies were consistent. These changes in the reported symptoms with time probably reflect the real pattern of dyspepsia in this community and showed that 189 men $(14 \%)$ consistently complained of 'current ulcer-like dyspepsia' during the entire three years and that a further 91 men $(7 \%)$ again consistently reported 'ulcer-like dyspepsia' at some time during the three years. Overall, the total amount of serious ('major') dyspepsia was substantially unchanged, that is, the number of men developing dyspepsia was approximately equal to those who had apparently become quite free of symptoms.

\section{SUMMARY}

A three-year survey of the point and period prevalence of the dyspepsia-peptic-ulcer syndrome in a semirural population of some 1,500 males is described. Postal questionnaires, supported by standard random interviews and at the end of three years by scrutiny of all linked medical records for the population, established the occurrence of dyspepsia and of peptic ulcer according to a number of criteria. There appears to be a high prevalence of both peptic ulcer and severe dyspepsia in this community. The prevalence rates are for severe dyspepsia 154 per 1,000 and for demonstrable peptic ulcer 102 per 1,000 . Comparison of survey material at the beginning and at the end of the three years suggests a substantial shift $(a)$ from dyspepsia of various kinds to no dyspepsia (an apparent recovery rate of 17 per 1,000 per annum); (b) from no dyspepsia to dyspepsia of varying severity (a case inception rate of 16 per 1,000 per annum). A peptic ulcer rate (have or have had) of 117 per 1,000 is higher than was expected and various explanations are mentioned including the suggestion that there is a true regional excess in the north-east of Scotland. A new rate expressing peptic ulcers per thousand dyspeptics (in this survey 305 per 1,000) may be of some interest and value in studies of medical care. The importance of dyspepsia rather than peptic ulcer as a measure of morbidity in this condition is discussed. All but seven of the peptic ulcers encountered were duodenal.

This study was made possible by a grant (no. 407) from the Scottish Advisory Committee on Medical Research. We wish to thank Dr. J. Gill, Dr. N. Laing, and Dr. G. Gill not only for permission to interview their patients but for their willing cooperation in all aspects of this work. We would also like to thank their patients. Thanks are also due to colleagues in the Department of Public Health and Social Medicine in Aberdeen.

\section{REFERENCES}

Backett, E. M. (1960). Epidemiology of peptic ulceration. In Peptic Ulceration, edited by C. Wells and J. Kyle. Livingstone, Edinburgh.

Doll, R. (1952). Peptic ulcer. Epidemiology. In Modern Trends in Gastro-Enterology, edited by F. Avery Jones. pp. 361-379. Butterworth, London.

- Jones, F. A., and Buckatzsch, M. M. (1951). Occupational factors in the aetiology of gastric and duodenal ulcers. Spec Rep. Ser. med. Res. Coun. (Lond.), 276, H.M.S.O., London.

Dunn, J. P., and Cobb, S. (1962). Frequency of peptic ulcer among executives, craftsmen and foremen. J. occup. Med., 4, 343-348.

Illingworth, C. F. W., Scott, L. D. W., and Jamieson, R. A. (1944). Acute perforated peptic ulcer: frequency and incidence in the West of Scotland. Brit. med. J., 1, 617-620 and 655-658.

Jones, G. M. (1959). Incapacity for work among the insured population of Great Britain. Brit. J. prev. soc. Med., 13, 74-87.

Mackay, C. (1966). Perforated peptic ulcer in the West of Scotland: a survey of 5,343 cases during 1954-63. Brit. med. J., 1, 701-705.

Ministry of Pensions and National Insurance. Digests of Statistics Analysing Certificates of Incapacity, June 1958-June 1961. Ministry of Pensions and National Insurance, London.

Office of Health Economics (1964). The Costs of Medical Care. O.H.E., London.

Office of Health Economics (1965). Work Lost Through Sickness. O.H.E., London.

Pulvertaft, C. N. (1959). Peptic ulcer in town and country. Brit. J. prev. soc. Med., 13, 131-138.

Registrar General (1947-66). Statistical Reviews of England and Wales for the years 1945-64. Part 1. H.M.S.O., London. 
U.S. National Health Survey (1960). Peptic Ulcers Reported in Interviews. (Health Statistics. Public Health Service Publ, No. 584-Series B-No. 17). U.S. Government Printing Office, Washington.

Weir, R. D. (1960). Perforated peptic ulcer in North-East Scotland. Scot. med. J., 5, 257-264.

\section{APPENDIX A}

QUESTIONS CONCERNING DYSPEPSIA

1 Have you ever been diagnosed as having a peptic, gastric (stomach), or duodenal ulcer?

2 Have you ever vomited any blood?

3 Have you had a perforated ulcer or any other stomach operation?
4 Have you ever had a barium-meal X-ray? (Before such an X-ray you have to take a thick white gruel.)

5 Have you ever had any digestion or pains in the stomach lasting more than a few days in the past five years:

(a) about which you have seen your doctor?

(b) for which you have regularly taken stomach powders or tablets?

(c) which seems to be brought on by a particular type of food, but about which you have neither seen your doctor nor taken powders/tablets?

(d) have you had these symptoms during the last three months? 